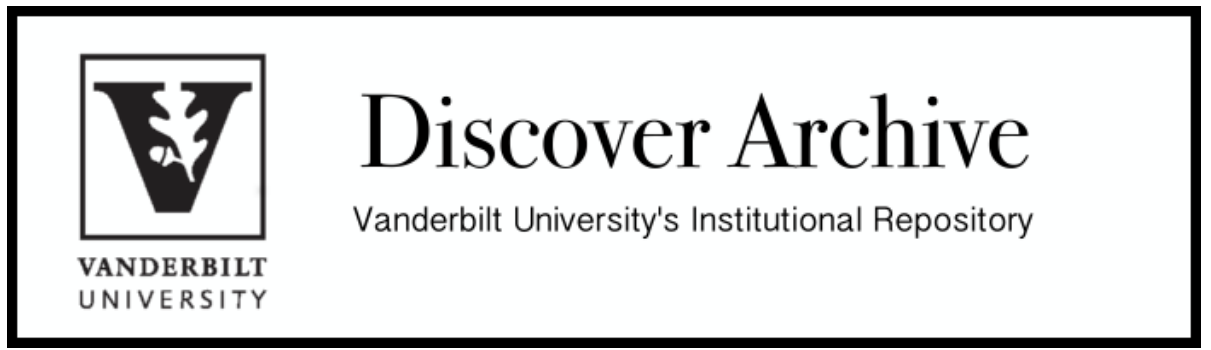

This work was originally published as: W. Kip Viscusi, The Role of Publication Selection Bias in Estimates of the Value of a Statistical Life - 1 American Journal of Health Economics 27 (2015). 


\title{
THE ROLE OF PUBLICATION SELECTION BIAS IN ESTIMATES OF THE VALUE OF A STATISTICAL LIFE
}

\author{
W. KIP VISCUSI
}

\begin{abstract}
Meta-regression estimates of the value of a statistical life (VSL) controlling for publication selection bias often yield bias-corrected estimates of VSL that are substantially below the mean VSL estimates. Labor market studies using the more recent Census of Fatal Occupational Injuries (CFOI) data are subject to less measurement error and also yield higher bias-corrected estimates than do studies based on earlier fatality rate measures. These results are borne out by the findings for a large sample of all VSL estimates based on labor market studies using CFOI data and for four meta-analysis data sets consisting of the authors' best estimates of VSL. The confidence intervals of the publication bias-corrected estimates of VSL based on the CFOI data include the values that are currently used by government agencies, which are in line with the most precisely estimated values in the literature.
\end{abstract}

KEYWORDS : value of a statistical life, VSL, meta-regression, publication selection bias, Census of Fatal Occupational Injuries, CFOI

JEL CLASSIFICATION : I18, K32, J17, J31

\section{Introduction}

The key parameter used in policy contexts to assess the benefits of policies that reduce mortality risks is the value of a statistical life (VSL). ${ }^{1}$ This measure of the risk-money trade-off for small risks of death serves as the basis for the standard approach used by government agencies to establish monetary benefit values for the predicted reductions in mortality risks from health, safety, and environmental policies. Recent government applications of the VSL have used estimates in the \$6 million to \$10 million range, where these and all other dollar figures in this article are in 2013 dollars using the Consumer Price Index for all Urban Consumers (CPI-U). For example, the Food and Drug Administration's 2011 regulatory impact analysis of labeling for bronchodilators to treat asthma used a VSL of \$8.1 million, the Occupational Safety and Health Administration's 2011 analysis of general working conditions in shipyard employment used a VSL of $\$ 9.5$ million, the Food

W. Kip Viscusi (kip.viscusi@vanderbilt.edu), University Distinguished Professor of Law, Economics, and Management, Vanderbilt University Law School.

1 Viscusi (2014b) presents a partial inventory of 98 government regulations and the associated VSL used to assess the policy impacts. The most frequently represented agencies are the Environmental Protection Agency, the Department of Transportation, and the Food and Drug Administration. 
Safety and Inspection Service's 2011 analysis of inspection and test result procedures used a VSL of \$7.3 million, the Federal Aviation Administration's 2012 analysis of flight crew duty and rest requirements used a VSL of \$6.6 million, and the US Environmental Protection Agency's 2012 regulatory impact analysis of new source performance standards for petroleum refiners used a VSL of $\$ 9.8$ million. For these and other regulations, the VSL is typically the critical parameter that determines the economic desirability of policies targeted at reductions in mortality risks. Policies for which the net cost per expected life saved exceeds the VSL will not pass a benefit-cost test.

Government agencies have drawn on the substantial economics literature on VSL to set these policy values. Although both stated preference studies and revealed preference studies have contributed estimates to the VSL literature, most of the policy emphasis in the United States has been placed on VSL estimates derived from labor market studies of VSL. This revealed preference approach establishes levels of VSL implied by the estimated trade-off between wages and worker fatality rates. Countries such as the United Kingdom for which the estimates from labor market studies are less reliable often utilize stated preference estimates of VSL for government policy.

Typically, US government agencies draw on the results of different studies in deriving their VSL estimate for benefit assessments. In some cases, this procedure has involved averaging the results across studies based on a survey of the literature or a meta-analysis, while in others the agency has used the results of a meta-regression analysis to control for different variables that may affect the estimated VSL, such as the average income of the sample. Among the meta-regression analyses that have been relied upon by US government agencies in recent years are those by Mrozek and Taylor (2002), Viscusi and Aldy (2003), and Kochi, Hubbell, and Kramer (2006). Agencies also may refer to more than one metaregression analysis as the basis for its VSL estimate. These meta-regression analyses serve to combine the results of different VSL estimates and to facilitate adjustments in the VSL to tailor the results to the particular population whose preferences are being valued by, for example, controlling for the different countries for which the estimates have been derived.

An additional factor that can be taken into account through meta-regression analyses is controlling for the effect of publication selection bias (Stanley and Doucouliagos 2012). Publication selection bias could result from either the selection of estimates that the researcher chooses to report or the unwillingness of peer-reviewed journals to publish results outside the conventional range of empirical estimates or which appear to be implausible based on economic theory. For example, negative estimates of compensating differentials for greater levels of fatality risk have no sound theoretical basis.

The potential influence of such biases has played a prominent role in the medical literature. Both outcome reporting bias and publication bias substantially affect the publication of results for randomized control trials of health-care interventions (Dwan et al. 2008, 2013). Their review found that there was outcome reporting bias as the results of many clinical drug trials are never published, as drug companies have little interest in pursuing or communicating the results of unproductive lines of research. There is also evidence of publication bias in the medical literature that arises because studies with statistically significant results were more likely to be submitted for publication and published than those with insignificant results. Factors that are believed to diminish the likely truthfulness of 
medical research findings that are published include the presence of a substantial financial interest in the study outcome, the presence of particularly exciting new results that are frequently refuted in subsequent research, and studies in which the effects are small, such as the role of genetic risk factors in multigenetic diseases (Ioannidis 2005).

Similar types of biases may affect the publication of estimates of VSL. Guided by economic theory, researchers may be reluctant to report negative estimates for VSL, which are inconsistent with the basic theory of compensating differentials that jobs posing higher levels of risk will only be attractive to workers if these jobs provide additional pay. Although studies may report some surprising VSL estimates, it is particularly unlikely that the authors would select a negative VSL as their preferred estimate. There also may be biases arising from anchoring on existing results in the literature. Several early VSL estimates were based on labor market studies using the Society of Actuaries mortality data for people in different occupations, as opposed to the occupation-specific job risk. Use of the Society of Actuaries data as a proxy for the worker's job-related risk overstated the average job-related fatality rate by an order of magnitude and led to very low estimates of VSL, which potentially induced an anchoring bias in subsequent research. Researchers tended to view such low values as being reasonable, particularly since they were also more similar to the present value of lifetime income-the human capital measure that VSL estimates typically supplanted in benefit assessments.

Although there have been more meta-analyses of VSL than any other economic subject, there has been comparatively little attention devoted to the influence of publication selection bias. To date there has been only one empirical study of the effect of publication selection bias on VSL levels, which is the focus of this article, and one article focusing on the influence of publication selection bias on the income elasticity of VSL as opposed to the VSL level, which is my primary focus here. The previous exploration of the role of publication bias with respect to VSL levels indicated that the publication selection biases are statistically significant and have a profound effect on the estimated VSL. Doucouliagos, Stanley, and Giles (2012) estimated the effect of publication bias on labor market estimates of the VSL and found that correction for publication selection bias reduces the estimated VSL by 70-80 percent, generating a VSL of $\$ 1.1$ million. $^{2}$ Given the pivotal role of VSL in benefit assessments, reducing the VSL to this level would dramatically diminish the assessed benefits of reduced mortality risks, which in turn would affect the character and stringency of government policies. In my analysis below, I do not question the soundness of the research that led to this quite substantial estimated publication selection bias effect. Indeed, some of my tests for publication selection bias are very similar to those in Doucouliagos, Stanley, and Giles (2012). However, I show that VSL studies based on superior fatality rate data have quite different implications even after correcting for potential publication bias effects.

The other meta-regression analysis of the effect of publication selection bias in the VSL literature did not address the bias in VSL estimates but instead focused on the estimated

2 This result is reported in two different articles. In column 1 of Table 9 of their article, Stanley and Doucouliagos (2013) draw on the results from column 1 of Table 1 of Doucouliagos, Stanley, and Giles (2012) as part of their broader methodological treatment of meta-regression techniques. 
income elasticity of VSL. Doucouliagos, Stanley, and Viscusi (2014) found evidence of statistically significant publication bias with respect to the income elasticity of VSL. But these results had less disturbing policy implications. While the estimated range of the biascorrected income elasticity of VSL from 0.25 to 0.63 was below the mean income elasticity estimate in the literature, this bias-corrected range included the income elasticity estimates in the meta-regression analyses in Viscusi and Aldy (2003) in which there was no correction for publication selection effects.

The principal theme of this article is that much of the role of the publication selection bias can be traced to studies based on earlier eras of fatality rate data. The available US occupational fatality rate measures have evolved from voluntary reporting of fatalities to the US Bureau of Labor Statistics (BLS), to reliance on fatality rates based on partial samples of the working population, and most recently, to the use of a complete Census of Fatal Occupational Injuries (CFOI) undertaken by the BLS. The CFOI is a comprehensive census of all worker fatalities. Construction of the CFOI requires that the BLS validate every fatality as being job-related using multiple data sources such as death certificates, workers' compensation records, and coroners' reports.

Because the CFOI data consist of individual records of fatalities, researchers have used these data to construct much more precise measures of the fatality rate that can be matched to the worker in the employment sample. Whereas previous BLS job fatality data pertained to average fatality rates by industry, it is now possible to construct fatality rates by very refined dimensions such as industry, occupation, age, gender, race, and immigrant status. ${ }^{3}$ For example, some studies have constructed a fatality rate stratified by 50 industries and by 10 occupations so that both industry and occupational variations in the fatality rate are taken into account. Using multiple years of CFOI data to have an adequate sample size, it is feasible to construct risk estimates for such narrowly defined categories. Most previous labor market studies of VSL before the advent of the CFOI data relied on industry-level data and, in effect, assumed all jobs within an industry were equally risky.

In recognition of the superiority of the CFOI fatality rate measure in estimates of the VSL, the US Department of Transportation (2013) relies solely on VSL estimates based on the CFOI in its official guidance procedures. The agency has adopted for policy evaluation purposes an average of VSL estimates from nine labor market studies that utilized the CFOI data. Previously, the agency had relied on a smaller sample of individual articles and meta-regression analyses including studies utilizing risk measures that were less reliable than those derived from the CFOI. As this article will demonstrate, VSL estimates using the CFOI data exhibit a differing performance not just with respect to the level of VSL but also with respect to the influence of publication selection bias as well.

This article begins with an analysis of publication selection bias focusing specifically on estimates based on the CFOI data, and then turns to an analysis of broader data sets that permit analysis of the different performance of the CFOI data. Estimates of VSL for a homogeneous population should be independent of the estimated standard errors. This relationship forms the basis for the exploration of the role of publication selection bias.

3 Viscusi (2013) reviews these studies using CFOI data and the different dimensions on which the article constructed the fatality rate and matched it to the worker. 
In Section II I construct a new data set based on a large sample of individual regression results using the CFOI data. The magnitude and statistical significance of the publication selection bias varies across the different specifications and in some instances is not statistically significant. In all specifications, the extent of the bias for the CFOI studies is well below the $70-80$ percent publication bias estimate found by Doucouliagos, Stanley, and Giles (2012) for VSL studies. The main result is that the publication bias-corrected estimates using the CFOI data are very similar to the estimated values currently used for policy purposes. Section III focuses on four data sets used in a meta-regression analysis based on the authors' single best estimate of the VSL for each article. To maintain comparability to Doucouliagos, Stanley, and Giles (2012) and Doucouliagos, Stanley, and Viscusi (2014) so as to distinguish the role of the CFOI data, this analysis begins by using the meta-regression sample of Bellavance, Dionne, and Lebeau (2009) that was employed in those studies as the starting point for the analysis. I then augment these data with other articles, including more recent CFOI-based studies. The meta-regression estimates using these data indicate a statistically significant publication selection bias effect, but the estimated VSL after adjusting for this bias is much greater for studies using the CFOI data. As noted in the concluding Section IV, while there is sometimes evidence of publication selection bias, the publication selection-corrected estimates of VSL based on the CFOI data are less subject to an upward bias than estimates based on other fatality rate measures.

\section{Publication Selection Bias Estimates for a Sample of CFOI Studies}

\section{A. THE CFOI VSL ESTIMATE SAMPLE}

Given the superior properties of the CFOI data for estimates of VSL, it is useful to explore the role of publication bias using a sample consisting of only studies that utilized the CFOI data. However, rather than focusing on a single preferred estimate from each study, I include a comprehensive set of regression estimates, thus avoiding any selection effects in terms of which estimates are included in the meta-regression analysis. This "all-set" sample incorporates the entire range of estimates from each study and their heterogeneity. The resulting sample consists of 550 observations drawn from 17 different studies. The sample includes all published articles and available working papers that include estimates of VSL based on the CFOI data. The Online Appendix (www.mitpressjournals.org/doi/suppl/10.1162/ajhe_a_00002) summarizes the list of the studies used in this analysis and the procedure for constructing this sample. ${ }^{4}$

Table 1 summarizes the sample characteristics. The estimated VSL for the CFOI sample has a mean value of $\$ 14.0$ million. The main variable that will be used to analyze publication selection effects is the standard error (standard error) of the VSL, which is the key variable used to capture the precision of the VSL estimates and the influence of publication selection bias. The average labor market income (income) for the sample is the average annual earnings of the worker. The other variables pertain to some of the pivotal explanatory

4 References used in the meta-analysis but not cited in the text are: Aldy and Viscusi 2008, Evans and Schaur 2010, Hersch and Viscusi 2010, Kniesner, Viscusi, and Ziliak 2006, Kochi and Taylor 2011, Leeth and Ruser 2003, Scotton 2013, and Viscusi and Philip 2014. 
TABLE 1. Summary statistics for the CFOI sample

\begin{tabular}{lcc}
\hline Variable & Mean & Standard deviation \\
\hline VSL estimates (\$ millions) & 14.035 & 10.246 \\
Standard error & 5.812 & 4.964 \\
Income (\$ thousands) & 43.767 & 14.293 \\
Workers' compensation & 0.630 & 0.483 \\
Nonfatal injury & 0.339 & 0.474 \\
Wage specification & 0.105 & 0.307 \\
Correct standard errors & 0.574 & 0.495 \\
Clustered standard errors & 0.842 & 0.365 \\
\hline
\end{tabular}

Notes: $N=550$. VSL estimates and Income have been converted to 2013 dollars.

variables included in the wage equations used to estimate VSL. The studies are characterized by whether they include a workers' compensation variable (workers' compensation) either explicitly or by including 50 state indicator variables. Just over one-third of the regression equations included a measure of nonfatal job injury rates (nonfatal injury).

The hedonic wage equation traces out the set of wage-risk combinations generated by the tangencies between the market offer curve and worker indifference curves. The functional form of the dependent variable is not clear theoretically based on the relationship between wages and fatality rates. However, the semi-logarithmic form has a basis in the human capital literature and is closer to the form suggested by Box-Cox specification tests.

Consequently, authors usually have estimated the VSL using a semi-logarithmic wage equation or, in some cases a linear wage equation format, which we will denote using a Wage Equation dummy variable. The linear wage equation takes the form

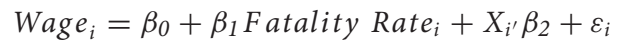

where $X_{i}$ is a vector of personal and job characteristics for worker $i$. For studies reporting wage equation estimates, the VSL (or the annualized value of $\partial$ Wage/2Fatality Rate) equals the wage-risk trade-off implied by the coefficient on the fatality rate variable, after appropriate adjustment for the units to reflect annual earnings premiums corresponding to annual fatality risks. The estimated standard error of Fatality Rate can be used to calculate the standard error of the VSL directly after annualizing the job risk premium. If the estimates are based on a semi-logarithmic wage equation, the estimation takes the form

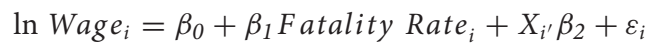

For this semi-logarithmic wage equation, the calculation of the average VSL of the sample based on $\partial$ Wage/2Fatality Rate is given by

$$
V S L=\hat{\beta}_{1} \times \overline{\text { Wage }}
$$


where $\overline{\text { Wage }}$ is the average wage for the sample and the units must be adjusted to reflect annual levels of compensation, for example, typically by multiplying the hourly wage by 2,000 full-time hours. Calculation of the VSL is consequently given by the product of the average wage rate for the sample and the fatality rate coefficient, along with appropriate adjustment for the fatality rate and wage units. Because the wage is a random variable, as is the fatality rate coefficient, the variance of the VSL for semi-logarithmic wage equations is the variance of the product of these random variables. Unlike the linear wage equations for which it is possible to calculate the correct standard errors of the VSL based on the estimates of the coefficient and standard error of the fatality rate variable, correct calculation of the standard errors of VSL for the semi-logarithmic wage equations must be done using the original sample. Over half of the VSL estimates using the CFOI data both utilized a semi-logarithmic equation and reported standard errors of the VSL calculated correctly to account for this relationship (correct standard errors). ${ }^{5}$

There are additional econometric issues pertaining to the standard errors. The labor market studies of VSL involve the assignment of the same fatality rate to multiple workers in the same general job category, such as for all workers in the same industry or occupational group. This practice leads the errors for the different worker observations in the sample to consequently not be independent. The assignment of a common fatality rate to workers in a broadly defined group often leads to downward biases in the estimated standard errors (Moulton 1986). Calculation of standard errors that are clustered based on the unit of assignment for the fatality rate, such as the worker's industry, addresses this problem. To account for whether the study has reported such appropriately clustered standard errors, I have constructed a dummy variable to capture whether the authors have reported clustered standard errors, as is appropriate in such situations (clustered standard errors). ${ }^{6}$ Most estimates using the CFOI data report such clustered errors.

\section{B. FUNNEL PLOT OF VSL USING CFOI DATA}

A graphical illustration provides an overview of the potential role of publication selection bias. Meta-regression analyses of VSL generally assume that the estimates reported are an unbiased sample. If there is no publication bias and the assumptions underlying the regression model are satisfied, the estimates should be independent of their standard error and should be symmetrically distributed around the mean estimated value. This property is best suited to analyzing situations in which there is a single true population parameter. To obtain a general sense of the possible presence of publication selection bias, consider a visual plot in which the precision of the estimate (the inverse of the standard error) is on the vertical axis and the VSL (in millions of 2013 dollars) is on the horizontal axis.

5 Other VSL estimates were calculated based on wage equations for which no correction is needed to calculate the correct standard error of the VSL. In many instances involving semi-log wage equations, the authors did not report the standard error of VSL. In these situations, the standard error was constructed for this study using the equation estimates but not accounting for the fact that the wage is a random variable. In all, 32 percent of the observations were of this type. The first study in the data set in which the standard errors were calculated correctly for the semi-log wage equation was Viscusi and Aldy (2007).

6 The first study in the sample for which the authors reported clustered standard errors was Viscusi (2003). 
FIGURE 1. Funnel plot of VSL estimates for the CFOI sample

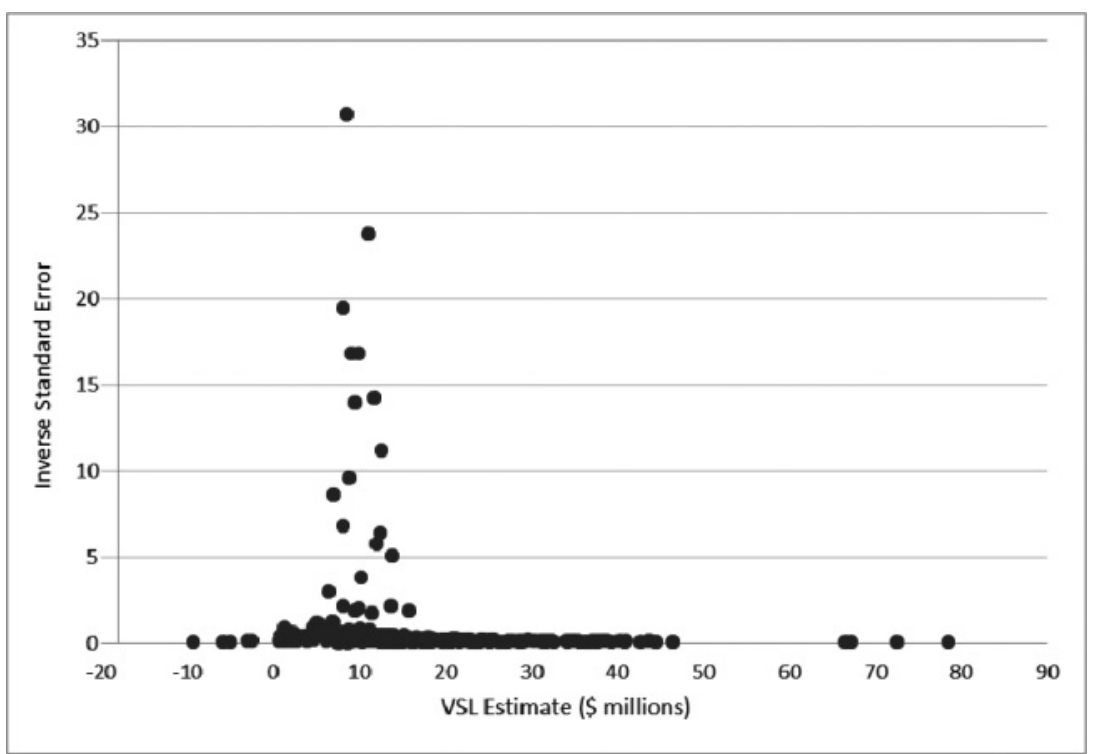

TABLE 2. Distribution of VSL estimates by different percentiles for the CFOI sample

\begin{tabular}{lc}
\hline Percentile & VSL estimate (\$ millions) \\
\hline 10 th & 5.030 \\
25 th & 8.000 \\
50 th & 11.335 \\
75 th & 17.259 \\
90 th & 28.638 \\
\hline
\end{tabular}

Examining the funnel plot provides an instructive visual summary of the data and publication selection effects. Because of the potential heterogeneity of VSL levels across different samples, the funnel plot is not a substitute for more formal multivariate tests. If there are no selection effects or reporting biases, the shape of the distribution should be similar to that of an inverted funnel.

Figure 1 provides a funnel plot of the VSL estimates for the CFOI sample, including the presence of five negative VSL estimates. The distribution is positively skewed, as the summary statistics for distribution of VSL estimates in Table 2 indicates. The median VSL value of $\$ 11.3$ million is below the sample mean of $\$ 14.0$ million, but there is a substantial concentration of observations between the first 25th percentile of $\$ 8$ million and the median. As a result, that part of the distribution exhibits a fairly reasonable funnel shape. 
The estimates in this range also exhibit the greatest precision. The mean VSL of the most precise 2 percent of the estimates is $\$ 9.7$ million, and the mean of the most precise 5 percent of the estimates is $\$ 9.9$ million. These high-precision estimates will be the principal determinants of the publication bias-corrected estimates. The top 5 percent of the estimates in terms of precision are drawn from Viscusi (2004), Kniesner and Viscusi (2005), Viscusi and Hersch (2008), and Kniesner, Viscusi, and Ziliak (2010,2014), all of which utilized very refined fatality rate measures, such as fatality rates matched to workers based on a grid of 50 industries by 10 different occupations.

The positive skew aspect of the distribution of VSL estimates in Figure 1 often stems from unique aspects of the particular studies, which we will account for in the statistical analysis with article-specific fixed effects. The principal outliers that produce a skewed distribution are the large positive estimates that are also coupled with relatively low levels of precision. The four outliers with VSL estimates greater than $\$ 50$ million are from Kniesner, Viscusi, and Ziliak (2010) and Scotton and Taylor (2011). ${ }^{7}$

\section{PUBLICATION BIAS-CORRECTED ESTIMATES USING VSL AS THE DEPENDENT VARIABLE}

The tests for publication bias will involve a series of different regressions that include tests that adhere to the accepted norms for meta-regression analyses of publication selection effects (Stanley and Doucouliagos 2012), as well as some unconventional tests to address the panel aspect of the data. Consider a model in which the $V S L_{i}$ is the dependent variable, where $i$ denotes study $i$. The estimating equation is of the form

$$
V S L_{i}=\alpha_{0}+\alpha_{1} \text { Std. Error } \text { Er }_{i}+X_{i^{\prime}} \alpha_{2}+\varepsilon_{i}
$$

where $S t d$. Error ${ }_{i}$ is the standard error of the VSL for study $i$ and $X_{i}$ is a vector of characteristics of study $i .^{8}$ The standard error is included in the equation to account for publication selection bias. If there is no publication bias, the coefficient $\alpha_{1}$ of Std. Error should equal zero. A statistically significant estimate of $\alpha_{1}$ is evidence of publication selection effects in that the reported VSL estimates are correlated with Std. Error as opposed to having a symmetrically distributed funnel plot. This coefficient is the regression analysis counterpart of the funnel asymmetry test. The full version of the model also includes a vector $X_{i}$ of variables including a series of dummy variables for the different articles, and ln(income), workers' compensation, nonfatal injury, wage specification, correct standard errors, and clustered standard errors. Many of these variables, including article-specific effects, will contribute to differences in estimated VSL levels. The estimated VSL after adjusting for publication selection bias effects is given by the constant term $\alpha_{0}$ in the basic model

7 The Kniesner, Viscusi, and Ziliak (2010) estimate of a VSL of \$72.6 million utilized the Panel Study of Income Dynamics. Subsequent estimates in Kniesner et al. (2012) that exploited the panel nature of the data utilizing fixed effects and related methods yielded much lower estimates of VSL.

8 The model could also be formulated in terms of the variance rather than the standard error, yielding similar empirical results (Viscusi 2014a). 
excluding the $X_{i}$ covariates. With the $X_{i}$ values included, estimates of the bias-corrected VSL also incorporate the mean effects of these covariates as well as the constant term.

The errors associated with the different VSL estimates are likely to exhibit substantial heterogeneity. As a result, the estimation of equation 4 utilizes a weighted least squares (WLS) model using the inverse of the variance of each of the VSL estimates as the weights. This meta-regression approach is known as the precision-effect estimate with standard error (Stanley and Doucouliagos 2012).

Table 3 reports the WLS estimates of equation 4. The robust heteroskedasticityadjusted standard errors for these estimates are in parentheses, and the clustered standard errors are in brackets, where the unit of clustering is on the particular article because the sample includes multiple VSL observations per article. All coefficient estimates and the associated confidence intervals (CI) that are reported for this sample include both the robust standard errors as well as the clustered standard errors.

The bias-corrected VSL estimates are very similar to the values of the most precise VSL estimates and are below the sample mean estimates. For the base regression in Table 3, the estimated VSL corrected for publication bias is $\$ 9.6$ million. This bias-corrected estimate is very similar to the most precise 2 percent VSL value of $\$ 9.7$ million and the most precise 5 percent value of $\$ 9.9$ million. The adjustment for publication selection bias reduces the VSL to about one-third below the sample mean value, with a fairly tight confidence interval. The standard error term that is included to capture the role of potential publication bias is statistically significant in the first equation, but the magnitude is small.

The second column of estimates in Table 3 including the series of covariates differs in terms of the role of publication bias. ${ }^{9}$ The standard error term is not statistically significant after the covariates have been included in the second column of Table 3, which suggests that the heterogeneity of VSL estimates contributes to the funnel plot asymmetry. Significant determinants of VSL based on the clustered standard errors are the negative effects of nonfatal injury and the wage specification. The overall predicted mean VSL is $\$ 13.7$ million if the effect of publication bias is excluded from the predicted value by setting its coefficient equal to zero.

Based on these estimates it is also possible to calculate the "preferred" VSL in which the predicted values are based on a preferred specification. Setting the key study characteristic variables (workers' compensation, nonfatal injury, correct standard errors, and clustered standard errors) equal to 1 leads to a predicted VSL of $\$ 11.0$ million. The confidence intervals for VSL based on the clustered standard errors include the range of values currently used by government agencies, but are much broader than in the base case. ${ }^{10}$

Closely related to the estimate of this equation is an unbalanced panel model including fixed effects for the different articles $(s)$ in the sample. This approach, which differs from standard meta-analysis techniques, captures the article-specific factors that influence the

9 Dummy variables for two articles had to be omitted to avoid singularity problems with respect to the correct standard errors variable.

10 The Stata post-estimation command nlcom uses the delta method to calculate the standard errors and the confidence intervals based on the particular combination of coefficients that is specified. The table notes list the assumptions used in constructing these values. 
TABLE 3. Weighted least squares (WLS) regressions of VSL for the CFOI sample

\begin{tabular}{|c|c|c|}
\hline Variable & Base regression & $\begin{array}{l}\text { Covariates and dummy variables } \\
\text { for articles included }\end{array}$ \\
\hline Intercept & $\begin{array}{l}9.572 \\
(0.455)^{\mathrm{a}} \\
{[0.082]^{\mathrm{a}}}\end{array}$ & $\begin{array}{l}15.107 \\
(2.776)^{\mathrm{a}} \\
{[4.640]^{\mathrm{a}}}\end{array}$ \\
\hline Standard error & $\begin{array}{l}0.457 \\
(0.181)^{\mathrm{b}} \\
{[0.290]}\end{array}$ & $\begin{array}{r}-0.155 \\
(0.303) \\
{[0.710]}\end{array}$ \\
\hline $\begin{array}{l}\text { In income } \\
\quad \text { (\$ thousands) }\end{array}$ & - & $\begin{array}{l}0.989 \\
(0.565)^{\mathrm{c}} \\
{[1.413]}\end{array}$ \\
\hline Workers' compensation & - & $\begin{array}{c}-1.241 \\
(2.588) \\
{[0.818]}\end{array}$ \\
\hline Nonfatal injury & - & $\begin{array}{c}-2.040 \\
(2.467) \\
{[0.109]^{\mathrm{a}}}\end{array}$ \\
\hline Wage specification & - & $\begin{array}{c}-2.184 \\
(0.690)^{\mathrm{a}} \\
{[0.943]^{\mathrm{b}}}\end{array}$ \\
\hline Correct standard errors & - & $\begin{array}{r}-2.478 \\
(4.418) \\
{[3.835]}\end{array}$ \\
\hline Clustered standard errors & - & $\begin{array}{l}1.012 \\
(1.273) \\
{[2.249]}\end{array}$ \\
\hline Adj. $R^{2}$ & 0.01 & 0.10 \\
\hline Mean VSL & $\begin{array}{c}9.572 \\
(0.455) \\
{[0.082]}\end{array}$ & $\begin{array}{l}13.725 \\
(1.211) \\
{[2.657]}\end{array}$ \\
\hline CI mean VSL & $(8.680,10.464)[9.412,9.732]$ & $(11.352,16.098)[8.518,18.932]$ \\
\hline Preferred VSL & $\begin{array}{l}- \\
- \\
-\end{array}$ & $\begin{array}{l}11.021 \\
(1.757) \\
{[0.814]}\end{array}$ \\
\hline CI preferred VSL & - & $(7.577,14.466)[9.426,12.617]$ \\
\hline
\end{tabular}

Notes: $N=550$. Robust standard errors are reported in parentheses, and standard errors clustered by article are reported in brackets. Mean VSL is the bias-corrected estimate of VSL evaluated at the mean of the explanatory variables, and preferred VSL is the estimate of VSL under the author's preferred specification also setting the values of workers' compensation, nonfatal injury, correct standard errors, and clustered standard errors equal to 1 . Statistical significance at the ${ }^{\mathrm{a}} 0.01$ level, ${ }^{\mathrm{b}} 0.05$ level, and ${ }^{\mathrm{c}} 0.10$ level. CI denotes the $95 \%$ confidence interval. 
average estimated VSL for the sample. These influences include differences in sample composition as well as differences in econometric specification. The fixed-effects equation for this unbalanced panel for equations $j$ in article $s$, is given by

$$
V S L_{j s}=\alpha_{0}+\alpha_{1} \text { Std. } \text { Error }_{j s}+X_{i}^{\prime} \alpha_{2}+a_{s}+\varepsilon_{j s}
$$

This equation is also estimated using a random-effects framework where the articlespecific intercepts are random effects rather than fixed effects. Although both fixed-effects and random-effects models are reported below, based on the Hausman test one can reject the hypothesis that the article-specific effects are uncorrelated with the other regressors in the equation. The differences between the coefficients in the models are strongly statistically significant at the 0.0004 level for the base equation and at the 0.0095 level for the regression including covariates.

The results are similar for the fixed-effects and random-effects models. The base case regression results in Table 4 indicate bias-corrected estimates of VSL of $\$ 10.5$ million for the fixed-effects model and a somewhat lower value of $\$ 9.1$ million for the random-effects model. The standard error term is statistically significant in both models, but with a coefficient below 1.0. Workers' compensation, nonfatal injury, and clustered standard errors have significant negative effects in the fixed-effects model, and the workers' compensation and the correct standard errors variables have significant negative coefficients in the random-effects model. The mean predicted VSL levels for the fixed-effects model are \$11.2 million after adjusting for publication selection bias and $\$ 8.1$ million after also adjusting for the preferred specification variables.

The results for the random-effects model follow a similar pattern, with $\$ 10.4$ million as the mean bias-adjusted estimate and $\$ 7.6$ million as the mean after adjusting for the preferred specifications. The random-effects model has the most consistently significant income effects, which imply an income elasticity of $0.829(0.131)[0.438]$ for the mean estimates and $1.136(0.225)[0.572]$ for the preferred estimates. ${ }^{11}$

\section{ESTIMATES USING THE T-RATIO OF THE VSL AS THE DEPENDENT VARIABLE}

An alternative estimation approach to analyzing the publication bias-corrected estimates is to regress the t-value for the VSL on $1 /$ Std. Error, or

$$
\text { t-ratio }{ }_{i}=\gamma_{0}+\gamma_{1}\left(1 / \text { Std. } \text { Error }_{i}\right)+\varepsilon_{i}
$$

In this instance, the coefficient of $1 /$ Std. Error provides a direct bias-corrected estimate of VSL. This formulation is presented as a robustness check of the previous estimates rather than the primary set of results because of the potential simultaneity of the t-ratio and $1 /$ Std. Error variables. Because the t-ratio is the ratio of the estimated VSL to its standard error, the t-ratio equation will produce a direct estimate of VSL but also an estimate subject

11 Similarly, for the fixed-effects model, the estimated income elasticity is $0.763(0.119)$ [0.467] for the mean estimates and $1.060(0.226)[0.616]$ for the preferred estimates. 
TAB LE 4. Fixed- and random-effect regression models of VSL for the CFOI sample

\begin{tabular}{|c|c|c|c|c|}
\hline Variable & $\begin{array}{l}\text { Base fixed } \\
\text { effects }\end{array}$ & $\begin{array}{l}\text { Base random } \\
\text { effects }\end{array}$ & $\begin{array}{c}\text { Fixed effects } \\
\text { with covariates }\end{array}$ & $\begin{array}{l}\text { Random effects } \\
\text { with covariates }\end{array}$ \\
\hline Intercept & $\begin{array}{l}10.496 \\
(0.622)^{\mathrm{a}} \\
{[1.612]^{\mathrm{a}}}\end{array}$ & $\begin{array}{c}9.117 \\
(0.902)^{\mathrm{a}} \\
{[1.355]^{\mathrm{a}}}\end{array}$ & $\begin{array}{c}-13.490 \\
(5.389)^{\mathrm{b}} \\
{[20.146]}\end{array}$ & $\begin{array}{c}-16.870 \\
(4.804)^{\mathrm{a}} \\
{[18.047]}\end{array}$ \\
\hline Standard error & $\begin{array}{c}0.613 \\
(0.091)^{\mathrm{a}} \\
{[0.277]^{\mathrm{b}}}\end{array}$ & $\begin{array}{c}0.739 \\
(0.083)^{\mathrm{a}} \\
{[0.242]^{\mathrm{a}}}\end{array}$ & $\begin{array}{c}0.486 \\
(0.088)^{\mathrm{a}} \\
{[0.308]}\end{array}$ & $\begin{array}{c}0.529 \\
(0.084)^{\mathrm{a}} \\
{[0.281]^{\mathrm{c}}}\end{array}$ \\
\hline $\begin{array}{l}\text { ln income } \\
\quad \text { (\$ thousands) }\end{array}$ & - & - & $\begin{array}{c}8.577 \\
(1.330)^{\mathrm{a}} \\
{[5.534]}\end{array}$ & $\begin{array}{c}8.625 \\
(1.254)^{\mathrm{a}} \\
{[5.028]^{\mathrm{c}}}\end{array}$ \\
\hline $\begin{array}{l}\text { Workers' } \\
\text { compensation }\end{array}$ & - & - & $\begin{array}{c}-2.185 \\
(3.846) \\
{[0.230]^{\mathrm{a}}}\end{array}$ & $\begin{array}{c}-3.971 \\
(1.525)^{\mathrm{a}} \\
{[1.354]^{\mathrm{a}}}\end{array}$ \\
\hline $\begin{array}{r}\text { Nonfatal } \\
\text { injury }\end{array}$ & - & - & $\begin{array}{c}-2.092 \\
(3.554) \\
{[0.250]^{\mathrm{a}}}\end{array}$ & $\begin{array}{c}0.252 \\
(1.447) \\
{[1.331]}\end{array}$ \\
\hline $\begin{array}{l}\text { Wage } \\
\text { specification }\end{array}$ & - & - & $\begin{array}{r}-0.019 \\
(1.365) \\
{[0.563]}\end{array}$ & $\begin{array}{c}0.184 \\
(1.301) \\
{[0.658]}\end{array}$ \\
\hline $\begin{array}{l}\text { Correct } \\
\text { standard errors }\end{array}$ & - & - & - & $\begin{array}{c}-3.325 \\
(1.605)^{b} \\
{[2.101]}\end{array}$ \\
\hline $\begin{array}{l}\text { Clustered } \\
\text { standard errors }\end{array}$ & - & - & $\begin{array}{c}-6.031 \\
(1.983)^{\mathrm{a}} \\
{[0.448]^{\mathrm{a}}}\end{array}$ & $\begin{array}{r}-0.585 \\
(1.334) \\
{[2.699]}\end{array}$ \\
\hline Adj. $R^{2}$ & 0.05 & 0.07 & 0.14 & 0.15 \\
\hline Mean VSL & $\begin{array}{l}10.496 \\
(0.622) \\
{[1.612]}\end{array}$ & $\begin{array}{l}9.117 \\
(0.902) \\
{[1.355]}\end{array}$ & $\begin{array}{l}11.235 \\
(0.600) \\
{[1.792]}\end{array}$ & $\begin{array}{l}10.398 \\
(0.918) \\
{[1.768]}\end{array}$ \\
\hline CI mean VSL & $\begin{array}{l}(9.278,11.715) \\
{[7.337,13.655]}\end{array}$ & $\begin{array}{l}(7.349,10.805) \\
{[6.460,11.774]}\end{array}$ & $\begin{array}{c}(10.060,12.411) \\
{[7.723,14.748]}\end{array}$ & $\begin{array}{l}(8.600,12.197) \\
{[6.932,13.865]}\end{array}$ \\
\hline $\begin{array}{l}\text { Preferred } \\
\text { VSL }\end{array}$ & $\begin{array}{l}- \\
- \\
-\end{array}$ & $\begin{array}{l}- \\
- \\
-\end{array}$ & $\begin{array}{c}8.094 \\
(1.341) \\
{[1.790]}\end{array}$ & $\begin{array}{c}7.590 \\
(1.185) \\
{[1.589]}\end{array}$ \\
\hline $\begin{array}{l}\text { CI preferred } \\
\text { VSL }\end{array}$ & $\begin{array}{l}- \\
-\end{array}$ & $\begin{array}{l}- \\
-\end{array}$ & $\begin{array}{l}(5.467,10.722) \\
{[4.586,11.603]}\end{array}$ & $\begin{array}{c}(5.267,9.912) \\
{[4.476,10.703]}\end{array}$ \\
\hline
\end{tabular}

Notes: $N=550$. Robust standard errors are reported in parentheses, and standard errors clustered by article are reported in brackets. Mean VSL is the bias-corrected estimate of VSL evaluated at the mean of the explanatory variables, and preferred VSL is the estimate of VSL under the author's preferred specification also setting the values of workers' compensation, nonfatal injury, correct standard errors, and clustered standard errors equal to 1 . Statistical significance at the ${ }^{\mathrm{a}} 0.01$ level, ${ }^{\mathrm{b}} 0.05$ level, and ${ }^{\mathrm{c}} 0.10$ level. CI denotes the $95 \%$ confidence interval. 
to simultaneity bias given the definitional relationships between the t-ratio and Std. Error. A closely related alternative specification is to also include the standard error directly in the equation as well, or

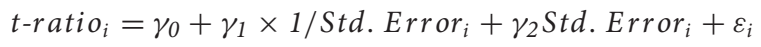

This formulation, known as the precision-effect estimate with standard error, has been shown to have low bias and to outperform most other meta-regression analysis estimators (Stanley and Doucouliagos 2013). I will also estimate equation 7 augmenting it with article-specific effects and a set of covariates.

Table 5 reports the WLS estimates of the t-ratio equation estimates, where 1/Std. Error is denoted by inverse Standard Error. Inverse Standard Error has stable coefficients across the three specifications, indicating a VSL from $\$ 8.1$ million to $\$ 8.4$ million. The confidence intervals around these estimates are quite tight. Across the three specifications, the lower bound of the confidence ratio is $\$ 8.0$ million and the upper bound is $\$ 8.7$ million.

Following the same approach as with the VSL estimates, Table 6 presents the fixed- and random-effects estimates for the t-ratio model estimates of VSL. However, unlike in the previous case it is not always possible to reject the random-effects specification. ${ }^{12}$ Thus, it is not possible to reject the hypothesis that the article-specific effects are uncorrelated with the other regressors in the equation for the model including covariates. The estimates of the bias-corrected mean VSL levels range from $\$ 9.5$ million to $\$ 9.6$ million across the three equations. The pattern is very similar to that of the WLS results, as the confidence intervals are very tight, having a range across the four specifications from $\$ 8.9$ million to $\$ 10.1$ million. It is noteworthy that this range includes the most precise top 2 percent and the top 5 percent of the observations in the sample shown in the funnel plot in Figure 1.

\section{Aggregate Meta-Analysis Data Sets}

\section{A. SAMPLE DESCRIPTION FOR BEST-SET ANALYSIS}

Four meta-analysis data sets can be used to explore the performance of the CFOI data relative to other fatality rate data. Unlike the CFOI data set, which included all VSL estimates from the pertinent articles, each of the aggregate meta-analysis data sets is based on a "best-set" approach in that a best or preferred single estimate from each study is used. Sample 1 is the Bellavance, Dionne, and Lebeau (2009) meta-regression analysis sample. Because this sample was used in the VSL publication selection bias analysis of Doucouliagos, Stanley, and Giles (2012) and the VSL income elasticity publication selection bias of Doucouliagos, Stanley, and Viscusi (2014), it provides a basis for assessing the relative performance of the CFOI data within the context of previous publication bias studies.

12 For the base regression case, the Hausman test statistic is $6.03, p$-value $=0.049$, and for the model including covariates, the test statistic is $9.99, p$-value $=0.189$. 
TAB LE 5. Weighted least squares (WLS) regressions of t-ratios for VSL for the CFOI sample

\begin{tabular}{|c|c|c|c|}
\hline Variable & $\begin{array}{l}\text { Base } \\
\text { regression }\end{array}$ & $\begin{array}{l}\text { Standard error } \\
\text { included }\end{array}$ & $\begin{array}{l}\text { Covariates and dummy variables } \\
\text { for articles included }\end{array}$ \\
\hline \multirow[t]{3}{*}{ Intercept } & 22.011 & 25.043 & 17.210 \\
\hline & $(11.742)^{\mathrm{c}}$ & $(13.049)^{c}$ & $(9.180)^{\mathrm{c}}$ \\
\hline & {$[3.993]^{\mathrm{a}}$} & {$[2.757]^{\mathrm{a}}$} & [11.777] \\
\hline \multirow{3}{*}{ Inverse standard error } & 8.358 & 8.245 & 8.145 \\
\hline & $(0.739)^{\mathrm{a}}$ & $(0.761)^{\mathrm{a}}$ & $(0.827)^{\mathrm{a}}$ \\
\hline & {$[0.167]^{\mathrm{a}}$} & {$[0.112]^{\mathrm{a}}$} & {$[0.014]^{\mathrm{a}}$} \\
\hline \multirow[t]{3}{*}{ Standard error } & - & -7.140 & -5.745 \\
\hline & & $(3.728)^{\mathrm{c}}$ & $(1.886)^{\mathrm{a}}$ \\
\hline & & {$[1.653]^{\mathrm{a}}$} & {$[2.437]^{\mathrm{b}}$} \\
\hline \multirow{3}{*}{$\begin{array}{l}\ln \text { income } \\
\quad(\$ \text { thousands })\end{array}$} & - & - & 6.212 \\
\hline & & & $(2.573)^{\mathrm{b}}$ \\
\hline & & & [3.911] \\
\hline \multirow{3}{*}{$\begin{array}{l}\text { Workers' } \\
\text { compensation }\end{array}$} & - & - & 1.217 \\
\hline & & & $(4.183)$ \\
\hline & & & {$[1.526]$} \\
\hline \multirow[t]{3}{*}{ Nonfatal injury } & - & - & -1.126 \\
\hline & & & $(3.912)$ \\
\hline & & & {$[0.288]^{\mathrm{a}}$} \\
\hline \multirow[t]{3}{*}{ Wage specification } & - & - & -1.538 \\
\hline & & & $(1.437)$ \\
\hline & & & {$[1.314]$} \\
\hline \multirow[t]{3}{*}{ Clustered standard errors } & - & - & -0.515 \\
\hline & & & $(5.329)$ \\
\hline & & & {$[7.671]$} \\
\hline \multirow[t]{3}{*}{ Correct standard errors } & - & - & -14.765 \\
\hline & & & $(6.791)^{\mathrm{b}}$ \\
\hline & & & {$[6.167]^{\mathrm{b}}$} \\
\hline Adj. $R^{2}$ & 0.90 & 0.90 & 0.89 \\
\hline \multirow[t]{3}{*}{ VSL } & 8.358 & 8.245 & 8.145 \\
\hline & $(0.739)$ & $(0.761)$ & $(0.827)$ \\
\hline & {$[0.167]$} & {$[0.112]$} & {$[0.014]$} \\
\hline \multirow[t]{2}{*}{ CI VSL } & $(6.910,9.807)$ & $(6.753,9.737)$ & $(6.523,9.766)$ \\
\hline & {$[8.030,8.686]$} & {$[8.024,8.465]$} & {$[8.116,8.173]$} \\
\hline
\end{tabular}

Notes: $N=550$. Robust standard errors are reported in parentheses, and standard errors clustered by article are reported in brackets. VSL is the bias-corrected estimate of VSL. Statistical significance at the ${ }^{\mathrm{a}} 0.01$ level, ${ }^{\mathrm{b}} 0.05$ level, and ${ }^{\mathrm{c}} 0.10$ level. CI denotes the $95 \%$ confidence interval. 
TABLE 6. Fixed-and random-effect regression models for t-ratios for VSL for the CFOI sample

\begin{tabular}{|c|c|c|c|c|}
\hline Variable & $\begin{array}{l}\text { Base fixed } \\
\text { effects }\end{array}$ & $\begin{array}{l}\text { Base random } \\
\text { effects }\end{array}$ & $\begin{array}{c}\text { Fixed effects } \\
\text { with covariates }\end{array}$ & $\begin{array}{l}\text { Random effects } \\
\text { with covariates }\end{array}$ \\
\hline \multirow[t]{3}{*}{ Intercept } & 0.520 & 0.283 & -2.610 & -3.254 \\
\hline & $(0.178)^{\mathrm{a}}$ & $(0.380)$ & $(2.798)$ & $(2.054)$ \\
\hline & {$[0.175]^{\mathrm{a}}$} & {$[0.308]$} & [3.580] & [2.421] \\
\hline \multirow{3}{*}{$\begin{array}{l}\text { Inverse standard } \\
\text { error }\end{array}$} & 9.470 & 9.550 & 9.480 & 9.629 \\
\hline & $(0.118)^{\mathrm{a}}$ & $(0.087)^{\mathrm{a}}$ & $(0.119)^{\mathrm{a}}$ & $(0.071)^{\mathrm{a}}$ \\
\hline & {$[0.282]^{\mathrm{a}}$} & {$[0.145]^{\mathrm{a}}$} & {$[0.291]^{\mathrm{a}}$} & {$[0.098]^{\mathrm{a}}$} \\
\hline \multirow[t]{3}{*}{ Standard error } & - & - & -0.029 & 0.004 \\
\hline & & & $(0.046)$ & $(0.042)$ \\
\hline & & & [0.035] & {$[0.034]$} \\
\hline \multirow{3}{*}{$\begin{array}{l}\text { ln income } \\
\quad \text { (\$ thousands) }\end{array}$} & - & - & 1.158 & 1.063 \\
\hline & & & $(0.690)^{\mathrm{c}}$ & $(0.560)^{\mathrm{c}}$ \\
\hline & & & {$[0.960]$} & {$[0.661]$} \\
\hline \multirow{3}{*}{$\begin{array}{l}\text { Workers' } \\
\text { compensation }\end{array}$} & - & - & -0.771 & -1.018 \\
\hline & & & $(1.990)$ & $(0.437)^{\mathrm{b}}$ \\
\hline & & & {$[0.113]^{\mathrm{a}}$} & {$[0.185]^{\mathrm{a}}$} \\
\hline \multirow{3}{*}{$\begin{array}{r}\text { Nonfatal } \\
\text { injury }\end{array}$} & - & - & -0.328 & -0.217 \\
\hline & & & (1.839) & $(0.424)$ \\
\hline & & & {$[0.047]^{\mathrm{a}}$} & [0.299] \\
\hline \multirow{3}{*}{$\begin{array}{l}\text { Wage } \\
\text { specification }\end{array}$} & - & - & -0.254 & 0.150 \\
\hline & & & $(0.706)$ & $(0.577)$ \\
\hline & & & {$[0.130]^{\mathrm{c}}$} & {$[0.273]$} \\
\hline \multirow{3}{*}{$\begin{array}{l}\text { Correct } \\
\text { standard errors }\end{array}$} & - & - & - & -0.434 \\
\hline & & & & $(0.414)$ \\
\hline & & & & {$[0.235]^{\mathrm{c}}$} \\
\hline \multirow{3}{*}{$\begin{array}{l}\text { Clustered } \\
\text { standard errors }\end{array}$} & - & - & -0.457 & 0.771 \\
\hline & & & $(1.027)$ & $(0.454)^{\mathrm{c}}$ \\
\hline & & & {$[0.084]^{\mathrm{a}}$} & {$[0.362]^{\mathrm{b}}$} \\
\hline Adj. $R^{2}$ & 0.92 & 0.92 & 0.92 & 0.92 \\
\hline \multirow[t]{3}{*}{ VSL } & 9.470 & 9.550 & 9.480 & 9.629 \\
\hline & $(0.118)$ & $(0.087)$ & $(0.119)$ & $(0.071)$ \\
\hline & {$[0.282]$} & [0.145] & [0.291] & {$[0.098]$} \\
\hline \multirow[t]{2}{*}{ CI VSL } & $(9.238,9.701)$ & $(9.380,9.721)$ & $(9.246,9.714)$ & $(9.490,9.767)$ \\
\hline & {$[8.918,10.022]$} & {$[9.266,9.835]$} & {$[8.910,10.051]$} & {$[9.437,9.820]$} \\
\hline
\end{tabular}

Notes: $N=549$. Robust standard errors are reported in parentheses, and standard errors clustered by article are reported in brackets. VSL is the bias-corrected estimate of VSL. Statistical significance at the ${ }^{\mathrm{a}} 0.01$ level, ${ }^{\mathrm{b}} 0.05$ level, and ${ }^{\mathrm{c}} 0.10$ level. CI denotes the $95 \%$ confidence interval. 
TABLE 7. Summary statistics for the best-set samples $1-4$

\begin{tabular}{lcccc}
\hline Variable & Sample 1 & Sample 2 & Sample 3 & Sample 4 \\
\hline VSL estimates (\$ millions) & 12.883 & 12.413 & 12.238 & 10.212 \\
& $(14.015)$ & $(12.313)$ & $(11.810)$ & $(6.428)$ \\
Standard error & 4.108 & 3.847 & 3.775 & 3.011 \\
& $(5.315)$ & $(4.720)$ & $(4.537)$ & $(2.292)$ \\
Income (\$ thousands) & 39.681 & 41.221 & 40.839 & 44.077 \\
& $(12.620)$ & $(11.761)$ & $(12.751)$ & $(8.055)$ \\
Indicator variables: & & & & \\
Workers' compensation & 0.205 & 0.222 & 0.250 & 0.300 \\
Nonfatal injury & 0.410 & 0.426 & 0.467 & 0.425 \\
Correct standard errors & 0 & 0.111 & 0.100 & 0.150 \\
Clustered standard errors & 0.154 & 0.259 & 0.233 & 0.250 \\
CFOI & 0.077 & 0.333 & 0.300 & 0.450 \\
$N$ & 39 & 54 & 60 & 40 \\
\hline
\end{tabular}

Notes: Standard deviations in parentheses. Sample 1 is from Bellavance, Dionne, and Lebeau (2009); Sample 2 augments the Bellavance, Dionne, and Lebeau (2009) sample with additional US studies using CFOI fatality rate data; Sample 3 augments Sample 2 with studies in Viscusi and Aldy (2003) that were not included in Sample 2; and Sample 4 restricts Sample 3 to those studies using US data.

Sample 1 consists of 39 VSL estimates drawn from 39 different studies. ${ }^{13}$ Sample 2 augments Sample 1 by including estimates from 15 CFOI-based VSL articles that were not included in Sample 1. The additional estimates incorporated in the sample are all based on the semi-logarithmic wage equation estimates using the authors' preferred specifications. The CFOI best-set sample has a mean (standard deviation) of VSL given by $\$ 11.1$ (6.6) million. The best-set mean is consequently 21 percent smaller than the all-set mean in Section II. Sample 3 adds to Sample 2 the six studies that were included in the metaanalysis of labor market estimates in Viscusi and Aldy (2003) but which are not already included in Sample 2. Finally, Sample 4 restricts Sample 3 to only those studies using US data, leading to a sample size of 40 .

Table 7 summarizes the sample characteristics for the variables that play a role in the statistical analysis. The average of the VSL estimates ranges from $\$ 10.2$ million for Sample 4 to $\$ 12.9$ million for Sample 1. The mean standard errors of the VSL are under

13 Bellavance, Dionne, and Lebeau (2009) relied on VSL estimates from semi-logarithmic wage equations. Despite the unconventional terminology used to characterize the calculation of VSL in their equation 13, the authors did calculate the VSL in the conventional manner for semi-logarithmic wage equations, multiplying the fatality rate coefficient by the wage, and annualizing the compensating differential effect. The examples provided in their appendix on p. 461 are consistent with the conventional approach. 
FIGURE 2. Funnel plot of VSL estimates for the best-set sample 3

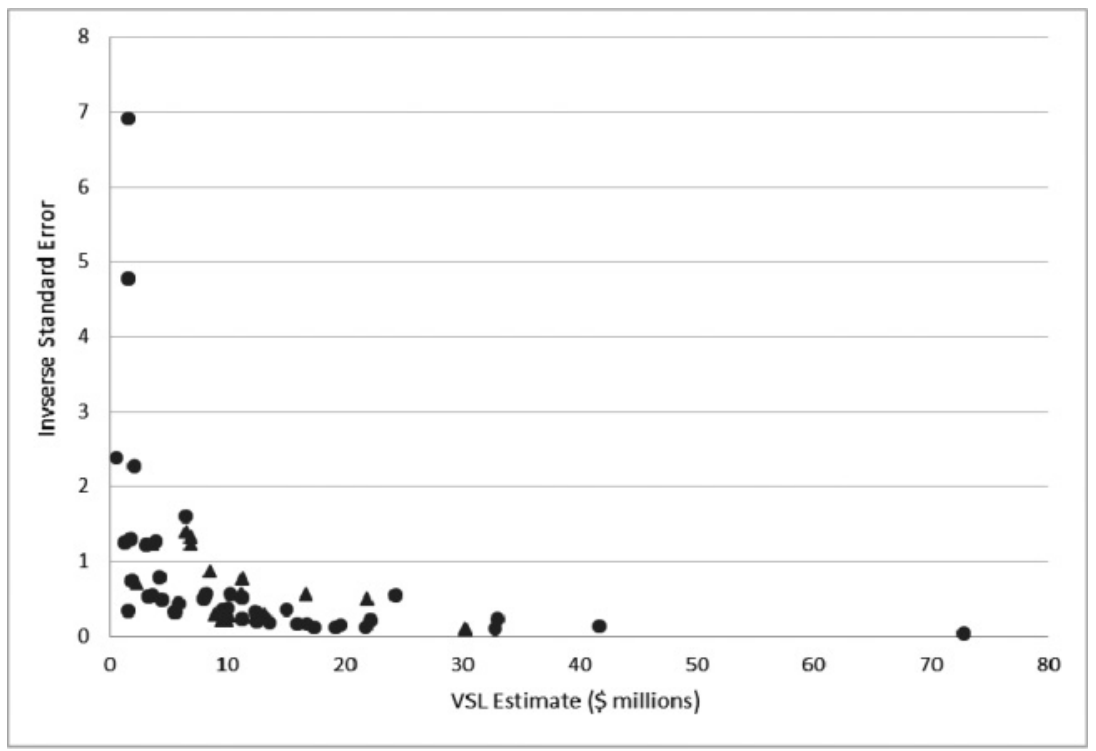

one-third the size of the mean VSL. Due to the skewed nature of the distribution, the sample mean is above the median VSL as well as the $\$ 9.5$ million (\$2013) median value in the meta-analysis in Viscusi and Aldy (2003). Interestingly, the lowest observed VSL estimates among the four samples considered here are for the US Sample 4 notwithstanding the higher income levels in the United States and the positive income elasticity of VSL. This result is not too surprising in that the explanatory variables included in the US analyses are often more comprehensive, including variables such as workers' compensation, which may reduce the estimated premium for fatality risks.

In addition to having a lower mean VSL than the CFOI sample, the characteristics of Samples 1-4 differ in several respects from the CFOI data set. Compared to Samples 1-4, the CFOI studies were somewhat less likely to include the nonfatal injury rate, but were considerably more likely to include workers' compensation, to utilize correct standard errors, and to report clustered standard errors. The various multivariate analyses below will control for the influence of these covariates.

The control variable that will be of primary interest is CFOI, which is an indicator variable that takes on a value of 1 for VSL estimates based on CFOI fatality rate data, and 0 otherwise. The share of studies in the different samples relying on CFOI data ranges from a low of 8 percent for Sample 1 to a high of 45 percent for Sample 4, with Samples 2 and 3 being intermediate cases with about one-third of the studies based on CFOI data.

\section{B. FUNNEL PLOT FOR BEST-SET SAMPLE 3}

Figure 2 presents a funnel plot of VSL estimates for Sample 3, which is the largest of these best-set samples. The circles indicate estimates based on the CFOI data, and the triangles 
indicate estimates using other fatality rate data. The funnel plot is highly skewed, with the outliers in terms of both precision and size of the VSL estimates being from studies that did not use the CFOI data. The non-CFOI studies have estimates along the vertical axis with low VSL and high precision as well as estimates along the horizontal axis with low precision and high VSL. The very low estimates of VSL are the most precisely estimated. The most precise 5 percent of the observations have a mean VSL of $\$ 1.3$ million, and the most precise 10 percent have a mean VSL of $\$ 3.2$ million. ${ }^{14}$ The two highest VSL estimates are from studies using data from the United Kingdom-Sandy and Elliott (1996), who report a VSL of \$57.4 million, and Arabsheibani and Marin (2000), who report a VSL of $\$ 32.9$ million. The CFOI estimates are more tightly clustered with more moderate levels of precision and less extreme VSL estimates.

Notably, the distribution of VSL estimates for the best-set sample is truncated as none of the estimates is negative-a result which is consistent with the theory of compensating differentials. However, given the pattern of VSL estimates that are often clustered along the vertical axis, one would have expected similar clustering for negative values if negative values had not been selectively screened out. Unlike the all-set CFOI sample estimates, best-set sample analyses are not well-suited to analyzing the possibility of negative VSL estimates. The emphasis of the best-set sample approach is on the author's preferred specification. This approach will tend to truncate the distribution and omit any negative VSL estimates, as negative VSL results are unlikely to be an economist's chosen specification.

\section{META-REGRESSION ESTIMATES OF PUBLICATION SELECTION BIAS}

To capture the potential effect of the CFOI fatality rate data on estimates of the VSL, I augment the specifications above by also including a CFOI variable. Thus, whereas $\alpha_{0}$ generally serves as the measure of the bias-corrected VSL, including CFOI as a covariate permits the estimate of the VSL to differ for studies based on the CFOI data. Thus, the counterpart to the model given by equation 4 is

$$
V S L_{i}=\alpha_{0}+\alpha_{1} \text { Std. Error } \text { Er }_{i}+X_{i^{\prime}} \alpha_{2}+\alpha_{3} \text { CFOI }_{i}+\varepsilon_{i}
$$

The coefficient $\alpha_{1}$ reflects the influence of publication selection effects. Similarly, the constant term $\alpha_{0}$ corresponds to the estimated average VSL controlling for both publication bias and the use of CFOI data. The main interest here is whether the use of CFOI data affects the estimated VSL after accounting for publication bias effects. In particular, is $\alpha_{3}$ statistically significant, and how does it influence the average VSL? Conditional on using the much more reliable CFOI data, what is the estimated VSL? That mean value is given by $\alpha_{0}+\alpha_{3}$. When reporting the VSL and its confidence interval for the equations including the CFOI variable, I will do so for estimates in which the CFOI variable takes on a value of 1 and publication selection effects are set equal to zero.

14 The most precise estimates, in descending order of precision, are from J. T. Liu, Hammitt, and J. L. Liu (1997), Shanmugam (2000), Kniesner and Leeth (1991), Kim and Fishback (1999), and Cousineau, Lacroix, and Girard (1992). 
TABLE 8. Weighted least squares (WLS) regressions of VSL for the best-set samples $1-4$

\begin{tabular}{lcccc}
\hline Variable & Sample 1 & Sample 2 & Sample 3 & Sample 4 \\
\hline Intercept & 1.045 & 1.120 & 1.090 & -0.237 \\
& $(0.232)^{\mathrm{a}}$ & $(0.207)^{\mathrm{a}}$ & $(0.161)^{\mathrm{a}}$ & $(0.492)$ \\
Standard error & 3.037 & 2.839 & 2.912 & 3.064 \\
& $(0.452)^{\mathrm{a}}$ & $(0.380)^{\mathrm{a}}$ & $(0.344)^{\mathrm{a}}$ & $(0.380)^{\mathrm{a}}$ \\
CFOI & 2.717 & 3.217 & 3.165 & 4.322 \\
& $(1.573)^{\mathrm{c}}$ & $(0.807)^{\mathrm{a}}$ & $(0.776)^{\mathrm{a}}$ & $(0.804)^{\mathrm{a}}$ \\
Adj. $R^{2}$ & 0.51 & 0.60 & 0.62 & 0.65 \\
VSL & 3.762 & 4.337 & 4.256 & 4.085 \\
& $(1.550)$ & $(0.785)$ & $(0.766)$ & $(0.734)$ \\
CI VSL & $(0.723,6.801)$ & $(2.800,5.875)$ & $(2.755,5.757)$ & $(2.646,5.524)$ \\
\hline
\end{tabular}

Notes: Robust standard errors are reported in parentheses. VSL is the bias-corrected VSL calculated based on the sum of the intercept and the CFOI coefficient. Statistical significance at the ${ }^{\mathrm{a}} 0.01$ level, ${ }^{\mathrm{b}} 0.05$ level, and ${ }^{\mathrm{c}} 0.10$ level. CI denotes the $95 \%$ confidence interval.

The rationale for distinguishing CFOI apart from a temporal trend is that the role of the temporal trend is that the studies have become refined over time, particularly in terms of the fatality rate data that they use. This approach differs from that of Doucouliagos, Stanley, and Giles (2012) in that instead of a time trend variable, I break the effect of CFOI out separately. There have been several improvements in the fatality rate data that influence the estimates of the VSL. Consider, for example, the effect on the VSL of the transition from the early BLS industry fatality rate data to the National Traumatic Occupational Fatality data, which was a precursor to the CFOI data developed by the National Institute of Occupational Safety and Health. Use of this newer fatality rate variable alone led to a doubling of the estimated VSL based on estimates of otherwise identical equations, due to the reduction in the amount of measurement error in the fatality rate variable (Moore and Viscusi 1988). Indeed the important role of measurement error in the fatality rate measure has been a prominent, long-standing theme in the VSL literature dealing with studies in the pre-CFOI era. ${ }^{15}$

The errors associated with the different VSL estimates are likely to exhibit substantial heterogeneity. As a result, the first sets of estimates for Samples 1-4 utilize a WLS model using the inverse of the variance of each of the VSL estimates as the weights.

All the estimates in Table 8 indicate evidence of statistically significant publication bias effects. These biases are all positive, indicating that the effect of the bias is to boost the estimated VSL. The magnitudes of the coefficients of the standard error terms range

15 See, for example, the discussion in Moore and Viscusi (1988), Black and Kniesner (2003), and Ashenfelter (2006). These critiques either predated the use of CFOI data in labor market estimates of VSL or were not aware of the CFOI data and did not include the CFOI-based studies in the critique. 
from 2.9 to 3.1, which is much greater than in the CFOI sample results. Unlike the CFOI estimates for which the standard error term has magnitudes below 1.0, the best-set results indicate large and statistically significant biases.

The mean estimates of the VSL implied by the constant terms in the equations for Samples 1-3 all indicate a VSL on the order of just \$1 million, about an order of magnitude below the mean values for each sample in Table 7. However, for the US Sample 4, the VSL estimate for the non-CFOI studies is not significantly different from zero. In every case, the CFOI estimates are significantly higher than the average, implying an overall VSL for the CFOI studies ranging from $\$ 3.8$ million to $\$ 4.3$ million. The 95 percent confidence intervals for VSL at the bottom of each panel in Table 8 do not include any values above $\$ 6.8$ million. $^{16}$

The WLS regressions in Table 9 augment the equations in Table 8 with a series of covariates. The standard error variable that captures the potential influence of publicationselection bias remains statistically significant with the same general magnitude as before. Workers' compensation sometimes has a significant negative effect, but the key variable of interest is CFOI, which adds from $\$ 2.9$ million to $\$ 3.8$ million to the VSL. The overall mean bias-corrected VSL levels for the samples range from $\$ 1.1$ million to $\$ 2.3$ million. However, after accounting for the additional VSL effect of being estimated using CFOI data, the VSL range rises to $\$ 4.1$ million to $\$ 4.9$ million. The preferred specification estimates setting the value of the key covariates equal to 1 are somewhat less for Samples 1-3, but not for Sample 4 , which is based on US studies.

The t-ratio estimates in Table 10 likewise indicate a VSL for studies other than the CFOI-based estimates of a VSL of $\$ 1.3$ million or a value that is not statistically significant for the US sample. However, the CFOI studies exhibit a substantial premium ranging from $\$ 2.5$ million to $\$ 4.2$ million. The total estimated VSL for the CFOI studies remains below the mean estimates, with a value from $\$ 3.8$ to $\$ 4.9$ million. In results that are not reported, addition of the standard error variable to the equations in Table 10 yields similar results, as this variable is never statistically significant.

\section{Conclusion}

These findings indicate a potentially statistically significant role of publication bias in estimates of the value of a statistical life. The bias adjustment may be quite substantial, particularly for studies not based on the CFOI data. The evidence of potential bias holds for the best-set samples based on individual estimates from a large series of studies as well as in some specifications for the all-set sample of regression results based solely on the CFOI fatality rate data. However, the clustered standard error results for the all-set estimates for studies relying on the CFOI data generate publication bias effects that are often not statistically significant or are marginally significant.

16 The best-set CFOI subsample was too small to permit reliable estimation. A regression including only the standard error and a constant term yields a VSL of \$4.65 million. For the variable set in Table 9, the VSL estimate is $\$ 6.65$ million, but none of the coefficients are statistically significant. Even adding ln Income to the equation in Table 8 leads to statistically insignificant VSL values. 
TABLE 9. Weighted least squares (WLS) regressions with covariates for the best-set samples 1-4

\begin{tabular}{|c|c|c|c|c|}
\hline Variable & Sample 1 & Sample 2 & Sample 3 & Sample 4 \\
\hline \multirow[t]{2}{*}{ Intercept } & 0.487 & 0.511 & 0.613 & -4.519 \\
\hline & $(2.170)$ & $(1.831)$ & $(1.202)$ & (11.303) \\
\hline \multirow[t]{2}{*}{ Standard error } & 3.029 & 2.812 & 2.893 & 2.883 \\
\hline & $(0.541)^{\mathrm{a}}$ & $(0.381)^{\mathrm{a}}$ & $(0.440)^{\mathrm{a}}$ & $(0.418)^{\mathrm{a}}$ \\
\hline \multirow{2}{*}{$\begin{array}{l}\ln \text { income } \\
\quad \text { (\$ millions) }\end{array}$} & 0.250 & 0.263 & 0.218 & 1.303 \\
\hline & $(0.847)$ & $(0.714)$ & $(0.462)$ & $(2.766)$ \\
\hline \multirow{2}{*}{$\begin{array}{l}\text { Workers' } \\
\text { compensation }\end{array}$} & -1.871 & -1.687 & -1.653 & -1.043 \\
\hline & $(1.022)^{\mathrm{c}}$ & $(0.877)^{\mathrm{c}}$ & $(0.565)^{\mathrm{a}}$ & (1.111) \\
\hline \multirow[t]{2}{*}{ Nonfatal injury } & -0.176 & 0.175 & 0.401 & 0.085 \\
\hline & $(2.591)$ & (1.982) & $(1.283)$ & $(1.635)$ \\
\hline \multirow{2}{*}{$\begin{array}{l}\text { Correct standard } \\
\text { errors }\end{array}$} & - & -0.042 & 0.065 & -0.018 \\
\hline & & $(2.044)$ & $(1.810)$ & $(2.745)$ \\
\hline \multirow{2}{*}{$\begin{array}{l}\text { Clustered standard } \\
\text { errors }\end{array}$} & 1.083 & 0.493 & 0.301 & 0.985 \\
\hline & $(2.733)$ & $(2.244)$ & $(1.825)$ & $(2.559)$ \\
\hline \multirow[t]{2}{*}{ CFOI } & 3.845 & 3.092 & 2.926 & 3.775 \\
\hline & $(1.971)^{\mathrm{c}}$ & $(1.422)^{\mathrm{b}}$ & $(1.281)^{\mathrm{a}}$ & $(1.756)^{\mathrm{b}}$ \\
\hline Adj. $R^{2}$ & 0.51 & 0.59 & 0.63 & 0.62 \\
\hline \multirow[t]{2}{*}{ Mean VSL } & 1.098 & 2.325 & 2.128 & 2.060 \\
\hline & $(1.020)$ & $(0.529)$ & $(0.565)$ & $(0.628)$ \\
\hline CI mean VSL & $(-0.901,3.097)$ & $(1.288,3.363)$ & $(1.020,3.236)$ & $(0.829,3.290)$ \\
\hline \multirow[t]{2}{*}{ CFOI VSL } & 4.943 & 4.387 & 4.176 & 4.136 \\
\hline & $(1.682)$ & $(1.034)$ & $(0.853)$ & (1.117) \\
\hline CI CFOI VSL & $(1.647,8.239)$ & $(2.361,6.413)$ & $(2.505,5.847)$ & $(1.947,6.325)$ \\
\hline \multirow[t]{2}{*}{ Preferred VSL } & 4.268 & 3.503 & 3.439 & 4.179 \\
\hline & $(1.591)$ & (1.168) & (1.013) & $(1.369)$ \\
\hline CI preferred VSL & $(1.150,7.387)$ & $(1.213,5.792)$ & $(1.454,5.423)$ & $(1.496,6.861)$ \\
\hline
\end{tabular}

Notes: Robust standard errors are reported in parentheses. Mean VSL is the bias-corrected estimate of VSL evaluated at the mean of the explanatory variables. CFOI VSL is the estimate of VSL evaluated at the mean of the explanatory variables, except for CFOI, which is evaluated at 1. Preferred VSL is the estimate of VSL under the author's preferred specification also setting the value of workers' compensation, nonfatal injury, correct standard errors, and clustered standard errors equal to 1 . Statistical significance at the ${ }^{\mathrm{a}} 0.01$ level, ${ }^{\mathrm{b}} 0.05$ level, and ${ }^{\mathrm{c}} 0.10$ level. CI denotes the $95 \%$ confidence interval. 
TABLE 10. Weighted least squares (WLS) regressions of t-ratios, for VSL for the best-set samples 1-4

\begin{tabular}{lcccc}
\hline & Sample 1 & Sample 2 & Sample 3 & Sample 4 \\
\hline Intercept & 2.000 & 2.052 & 1.960 & 3.979 \\
& $(1.397)$ & $(1.313)$ & $(1.135)^{\mathrm{c}}$ & $(0.728)^{\mathrm{a}}$ \\
Inverse standard error & 1.327 & 1.319 & 1.313 & -1.013 \\
& $(0.197)^{\mathrm{a}}$ & $(0.184)^{\mathrm{a}}$ & $(0.174)^{\mathrm{a}}$ & $(0.306)^{\mathrm{a}}$ \\
CFOI $\times$ inverse standard error & 2.520 & 3.470 & 3.553 & 4.173 \\
& $(1.533)$ & $(1.087)^{\mathrm{a}}$ & $(0.971)^{\mathrm{a}}$ & $(0.680)^{\mathrm{a}}$ \\
Adj. $R^{2}$ & 0.75 & 0.74 & 0.74 & 0.70 \\
VSL & 3.847 & 4.788 & 4.866 & 3.160 \\
& $(1.663)$ & $(1.245)$ & $(1.113)$ & $(0.841)$ \\
CI VSL & $(0.588,7.105)$ & $(2.348,7.229)$ & $(2.685,7.047)$ & $(1.511,4.809)$ \\
\hline
\end{tabular}

Notes: Robust standard errors are reported in parentheses. VSL is the bias-corrected estimate of VSL calculated based on the sum of the coefficients of inverse standard error and CFOI $\mathrm{x}$ inverse standard error. Statistical significance at the ${ }^{\mathrm{a}} 0.01$ level, ${ }^{\mathrm{b}} 0.05$ level, and ${ }^{\mathrm{c}} 0.10$ level. CI denotes the 95\% confidence interval.

In assessing the implications of the meta-regression analyses for estimates of VSL, the role of different eras of fatality rate data is consequential. The estimates for four different samples of studies found that there was a CFOI premium of $\$ 2$ million to $\$ 4$ million. These higher values are consistent with the reduced measurement error associated with the CFOI data.

The estimates based solely on the individual regression results utilizing individual regression estimates and the CFOI data generate larger VSL estimates than the results of the more broadly based best-set samples. The mean predicted all-set values are below the sample mean estimate of the VSL using the CFOI data of $\$ 14.0$ million. The estimated publication bias-corrected estimates of VSL are very similar to or somewhat above the $\$ 9.1$ million level for VSL adopted for policy assessment purposes by the US Department of Transportation (2013) based on its review of a series of VSL studies using CFOI data. The bias-corrected confidence intervals for the CFOI sample include even higher values that sometimes exceed the sample mean VSL. More recent policy applications of the VSL by other federal agencies also have been in the general range of the publication bias-corrected value of VSL, and in some cases have been below these values. There is no basis for reducing the VSL amounts currently used for policy based on publication selection effects. This result does not imply that agencies should not be cautious in their adoption of VSL estimates based on the literature, as the overall mean estimates may be unduly large.

After correcting for publication selection bias, the estimated VSL range is from $\$ 9.1$ million to $\$ 13.7$ million based on the VSL equations. The estimates from the preferred specifications yield values from $\$ 7.6$ million to $\$ 11.0$ million. Accounting for publication 
selection effects reduces the VSL to the levels reflected in the most precise estimates in the literature. The VSL estimates after correcting for publication bias are more in line with the average VSL levels that are generated once high estimate outliers are excluded. The VSL estimates associated with these studies also are in line with the VSL levels implied by studies that are generally viewed as most reliable based on their econometric approach.

\section{ACKNOWLEDGEMENTS}

Special thanks go to Jake Byl, Scott DeAngelis, and Clayton Masterman for construction of the data sets and research assistance. Tom Stanley provided insightful suggestions, as did the editor and several referees.

\section{REFERENCES}

Aldy, Joseph E., and W. Kip Viscusi. 2008. "Adjusting the Value of a Statistical Life for Age and Cohort Effects." Review of Economics and Statistics 90 (3): 573-81.

Arabsheibani, G. Reza, and Alan Marin. 2000. "Stability of Estimates of the Compensation for Danger." Journal of Risk and Uncertainty 20 (3): 247-69.

Ashenfelter, Orley. 2006. "Measuring the Value of a Statistical Life: Problems and Prospects." The Economic Journal 116: C10-23.

Bellavance, Francois, Georges Dionne, and Martin Lebeau. 2009. "The Value of a Statistical Life: A Meta-Analysis with a Mixed Effects Regression Model." Journal of Health Economics 28: 444-64.

Black, Dan A., and Thomas J. Kniesner. 2003. "On the Measurement of Job Risk in Hedonic Wage Models." Journal of Risk and Uncertainty 27: 205-20.

Cousineau, Jean-Michel, Robert Lacroix, and Anne-Marie Girard. 1992. "Occupational Hazard and Wage Compensating Differentials." Review of Economics and Statistics 74 (1): 166-69.

Doucouliagos, Chris, T. D. Stanley, and Margaret Giles. 2012. "Are Estimates of the Value of a Statistical Life Exaggerated?” Journal of Health Economics 31: 197-206.

Doucouliagos, Hristos, T. D. Stanley, and W. Kip Viscusi. 2014. "Publication Selection and the Income Elasticity of the Value of a Statistical Life." Journal of Health Economics 33: 67-75.

Dwan, Kerry, Douglas G. Altman, Juan A. Arnaiz, Jill Bloom, An-Wen Chan, Eugenia Cronin, Evelyne Decullier, et al. 2008. "Systematic Review of the Empirical Evidence of Study Publication Bias and Outcome Reporting Bias." PLOS ONE 3 (8): e3081.

Dwan, Kerry, Carrol Gamble, Paula R. Williamson, and Jamie J. Kirkham. 2013. "Systematic Review of the Empirical Evidence of Study Publication Bias and Outcome Reporting Bias-An Updated Review.” PLOS ONE 8 (7): e66844.

Evans, Mary F., and Georg Schaur. 2010. "A Quantile Estimation Approach to Identify Income and Age Variation in the Value of a Statistical Life." Journal of Environmental Economics and Management 59 (3): 260-70.

Hersch, Joni, and W. Kip Viscusi. 2010. "Immigrant Status and the Value of Statistical Life." Journal of Human Resources 45 (3): 749-71.

Ioannidis, John P. A. 2005. "Why Most Published Research Findings Are False." PLOS Medicine 2 (8): 0696-0701. 
Kim, Seung-Wook, and Price V. Fishback. 1999. “The Impact of Institutional Change on Compensating Wage Differentials for Accident Risk: South Korea, 1984-1990.” Journal of Risk and Uncertainty 18 (3): 231-48.

Kniesner, Thomas J., and John D. Leeth. 1991. "Compensating Wage Differentials for Fatal Injury Risk in Australia, Japan, and the United States." Journal of Risk and Uncertainty 4 (1): 75-90.

Kniesner, Thomas J., and W. Kip Viscusi. 2005. "Value of a Statistical Life: Relative Position vs. Relative Age.” American Economic Review 95 (2): 142-46.

Kniesner, Thomas J., W. Kip Viscusi, Christopher Woock, and James P. Ziliak. 2012. "The Value of Statistical Life: Evidence from Panel Data." Review of Economics and Statistics 94 (1): 74-87.

Kniesner, Thomas J., W. Kip Viscusi, and James P. Ziliak. 2006. "Life-Cycle Consumption and the Age-Adjusted Value of Life." Contributions to Economic Analysis \& Policy $5(1): 1-34$.

- 2010. "Policy Relevant Heterogeneity in the Value of Statistical Life: New Evidence from Panel Data Quantile Regressions.” Journal of Risk and Uncertainty 40 (1): 1531.

.2014. "Willingness to Accept Equals Willingness to Pay for Labor Market Estimates of the Value of Statistical Life." Journal of Risk and Uncertainty 48 (3): 187-205.

Kochi, Ikuho, Bryan Hubbell, and Randall Kramer. 2006. "An Empirical Bayes Approach to Combining and Comparing Estimates of the Value of a Statistical Life for Environmental Policy Analysis." Environmental and Resource Economics 34 (3): 385-406.

Kochi, Ikuho, and Laura O. Taylor. 2011. "Risk Heterogeneity and the Value of Reducing Fatal Risks: Further Market-Based Evidence." Journal of Benefit-Cost Analysis 2 (3): $1-28$.

Leeth, John D., and John Ruser. 2003. "Compensating Wage Differentials for Fatal and Nonfatal Injury Risk by Gender and Race.” Journal of Risk and Uncertainty 27 (3): 257-77.

Liu, Jin-Tan, James K. Hammitt, and Jin-Long Liu. 1997. "Estimating Hedonic Wage Function and Value of Life in a Developing Country." Economics Letters 57 (3): 353-58.

Moore, Michael J., and W. Kip Viscusi. 1988. "Doubling the Estimated Value of Life: Results Using New Occupational Fatality Data." Journal of Policy Analysis and Management 7 (3): 476-90.

Moulton, Brent R. 1986. "Random Group Effects and the Precision of Regression Estimates." Journal of Econometrics 32 (3): 385-97.

Mrozek, Janusz R., and Laura O. Taylor. 2002. "What Determines the Value of Life? A Meta-Analysis." Journal of Policy Analysis and Management 21 (2): 253-70.

Sandy, Robert, and Robert F. Elliott. 1996. "Unions and Risk: Their Impact on the Level of Compensation for Fatal Risk.” Economica 63 (250): 291-309.

Scotton, Carol R. 2013. "New Risk Rates, Inter-Industry Differentials and the Magnitude of VSL Estimates." Journal of Benefit-Cost Analysis 4 (1): 39-80.

Scotton, Carol R., and Laura O. Taylor. 2011. "Valuing Risk Reductions: Incorporating Risk Heterogeneity into a Revealed Preference Framework." Resources and Energy Economics 33 (2): 381-97. 
Shanmugam, K. R. 2000. "Valuations of Life and Injury Risks: Empirical Evidence from India." Environmental and Resource Economics 16 (4): 379-89.

Stanley, T. D., and Hristos Doucouliagos. 2012. Meta-Regression Analysis in Economics and Business. London: Routledge.

— 2013. "Meta-Regression Approximations to Reduce Publication Selection Bias." Research Synthesis Methods 20145 (1): 60-78.

US Department of Transportation. 2013. "Revised Departmental Guidance 2013: Treatment of the Value of Preventing Fatalities and Injuries in Preparing Economic Analyses". Accessed March 25, 2014. http://www.dot.gov/sites/dot.dev/files /docs/VSL\%20Guidance\%202013.pdf.

Viscusi, W. Kip. 2003. "Racial Differences in Labor Market Values of a Statistical Life." Journal of Risk and Uncertainty 27 (3): 239-56.

_ 2004. "The Value of Life: Estimates with Risk by Occupation and Industry." Economic Inquiry 42 (1): 29-48.

—. 2013. "Using Data from the Census of Fatal Occupational Injuries to Estimate the 'Value of a Statistical Life." Monthly Labor Review October: 1-17.

2014a. "The Role of Publication Selection Bias in Estimates of the Value of a Statistical Life.” NBER Working Paper No. w20116.

- 2014b. "The Value of Individual and Societal Risks to Life and Health." In Handbook of the Economics of Risk and Uncertainty, edited by Mark Machina and W. Kip Viscusi, 1, 385-452. Amsterdam: Elsevier.

Viscusi, W. Kip, and Joseph E. Aldy. 2003. "The Value of a Statistical Life: A Critical Review of Market Estimates throughout the World." Journal of Risk and Uncertainty 27 (1): $5-76$.

- 2007. "Labor Market Estimates of the Senior Discount for the Value of Statistical Life." Journal of Environmental Economics and Management 53 (3): 377-92.

Viscusi, W. Kip, and Joni Hersch. 2008. "The Mortality Cost to Smokers.” Journal of Health Economics 27 (4): 943-58.

Viscusi, W. Kip, and Elissa Philip. 2014. "The Value of a Statistical Life for Transportation Regulations: A Test of the Benefits Transfer Methodology.” SSRN Working Paper No. 2460837. 